\title{
El subordinado que subordina. Poseedores judíos de esclavos cristianos en el Registrum epistularum de Gregorio Magno
}

\author{
Rodrigo LAHAM COHEN \\ CONICET - Universidad de Buenos Aires \\ r_lahamcohen@hotmail.com
}

Recibido: 21 de mayo de 2015

Aceptado: 21 de septiembre de 2015

\begin{abstract}
RESUMEN
El Registrum epistularum, obra que compila las epístolas producidas por Gregorio Magno en el período en el que estuvo a cargo de la Cátedra romana (590-604 d.C.), es una herramienta fundamental al momento de abordar diversas temáticas. Entre las más de 860 cartas que despachó el scrinium papal, 26 refieren a judíos, representando -como ya ha advertido la crítica- un material de gran relieve para reconstituir los vínculos entre judíos y cristianos. En este trabajo centraremos la mirada en las epístolas que aluden a poseedores judíos de esclavos, con el fin de comprender tanto la situación de aquellos señalados en las comunicaciones como las posiciones de Gregorio Magno y de otros hombres de Iglesia frente al problema. Aspiramos a demostrar que si bien existían imperativos simbólicos que llevaban a legisladores laicos y a hombres de Iglesia a intentar impedir el control de cristianos por parte de judíos, el principal temor detrás de tales medidas era la tendencia de los judíos a convertir a sus servi, no por motivos proselitistas sino, principalmente, prácticos.
\end{abstract}

Palabras clave: Gregorio Magno. Judaísmo. Cristianismo. Esclavitud. Conversión.

\section{The Subordinate that Subordinates. Jewish Holders of Christian Slaves in Gregory the Great's Registrum Epistularum}

\begin{abstract}
The Registrum epistularum, the compendium that collects the epistles written by Gregory the Great during his Papacy (590-604 A.D.) is a fundamental source to approach various issues of the period. Among more than 860 letters sent by the papal scrinium, 26 refer to Jews. They are, as the majority of scholars asserts, a material of great value to reconstruct the relationship between Jews and Christians. In this paper I will center the analysis on the epistles alluding to Jewish holders of slaves in order to apprehend not only the situation of the Jews mentioned in those communications, but also to understand the positions of Gregory the Great and of others Churchmen on the problem. I seek to demonstrate that although there were symbolic imperatives that compelled both lay legislators and Churchmen to avoid Jewish control over Christians, the principal reason for this attitude was the tendency of the part of the Jews to convert their slaves, not for proselytizing purposes but rather, principally, mainly for practical motives.
\end{abstract}

Keywords: Gregory the Great. Judaism. Christianity. Slavery. Conversion.

Sumario: 1. Antecedentes legislativos. 2. Escenarios múltiples y estrategias dispares. 3. Temores fundados. 
Si se revelara que algunos de los esclavos cristianos hubieran sido comprados por él, guíelos sin ambigüedad y bajo los preceptos de las leyes hacia la libertad, para que, ¡Dios no quiera!, la religión cristiana, subordinada a los judíos, no sea contaminada. ${ }^{1}$

Cuando Gregorio Magno, obispo de Roma entre 590 y $604,{ }^{2}$ escribió las palabras que abren este trabajo, no se estaba refiriendo a un tema nuevo: el Codex Thedosianus, más de un siglo y medio antes, había dedicado un capítulo especial a la cuestión. Pero las órdenes del Papa tampoco representan el fin de la problemática de los esclavos cristianos en manos de judíos. En los siglos posteriores a su pontificado otros hombres de Iglesia volvieron a referir al tema. Incluso en una fecha tan avanzada como 1074, el concilio de Ruan insistió en la prohibición. ${ }^{3}$

En este breve artículo aspiramos a demostrar, a través del corpus heurístico gregoriano, que existían razones simbólicas y prácticas que motivaban la preocupación en torno a la posesión judía de esclavos cristianos. Si bien otros investigadores ya han postulado difusamente estas ideas, ${ }^{4}$ es necesario demostrar, a partir de un análisis preciso del epistolario, de qué modo ambas motivaciones se conjugaron. Es pertinente adelantar que, desde nuestra perspectiva, el componente simbólico revistió, al menos en Gregorio, una importancia sensiblemente menor a la de los imperativos de orden práctico.

1 Gregorio Magno, III, 37 [mayo, 593] 16-19: Mancipia autem Christiana quaecumque eum comparasse patuerit ad libertatem iuxta legum praecepta sine ambiguitate perducite, ne, quod absit, Christiana religio iudaeis subdita polluatur (texto latino tomado de la edición de D. Norberg, Gregorius Magnus. Registrum Epistularum [=CCSL 140 y 140A], Turnhout, 1982). Salvo indicación contraria, todas las traducciones de los textos clásicos/latinos son propias, realizadas del modo más fiel posible, sacrificando el estilo en pos de un mayor apego al texto original.

2 Dado el relieve histórico de Gregorio I, no creemos necesario presentarlo. Remitimos, para tal fin, a los textos más significativos sobre su figura: DUDDEN 1905; BATIFFOL 1928; DAGENS 1977; RICHARDS 1980; Fontaine et alii 1986; Straw 1988; AA.VV. 1991; CaVAdini 1995; Markus 1997; AA.VV. 2004; Boesch Gajano 2004; ACerbi 2006; Cremascoli - Degl'Innocenti 2008; NeIL - Dal Santo 2013.

3 El canon 14 del concilio, de hecho, legitima la medida a través de una referencia a Gregorio Magno (J. Mansi, ed., Sacrorum conciliorum nova et amplissima collectio, Graz, 1960-1961, 20, 519). Del canon 22 del concilio romano del 1078 solo se conserva el título: De Iudaeis non preponendis Christianis (E. Caspar (ed.), Gregorii VII Registrum (=MGH), Berlin, 1928, 2, 401). Otros cánones posteriores a Gregorio que también mencionaban la prohibición: canon 10, concilio romano de 743 (A. Werminghoff (ed.), Concilia aevi Karolini (=MGH), Hannover-Leipzig, 1906, 1, 16) y canon 73 del concilio de Meaux-París de 845-846 (W. Hartmann (ed.), Die Konzilien der karolinigischen Teilreiche 860-874 (=MGH), Hannover, 1998, 119-124), donde se cita parte de la epístola gregoriana dirigida a los monarcas merovingios. Para un análisis de esta legislación, véase a LINDER 1997.

4 El trabajo más específico sobre la esclavitud en el discurso y la praxis de Gregorio Magno es el de SERFASS 2006. Este, aunque refiere a la problemática de los judíos, no se dedica exclusivamente a ella. Centrados en la ley y con énfasis en el vínculo de Gregorio con los judíos: Katz 1933; Baltrusch 1994 y MaKuja 2009. El resto de los autores que se han especializado en Gregorio Magno y su relación con el judaísmo han realizado aproximaciones tangenciales a la temática. Los más significativos: BLUMENKranz 1960; BoESCH GAJANO 1979; BAmmel 1991; MARkus 1997, 76-80; CoHEN 1999, 73-94. Un análisis completo, tanto de la situación de los judíos a partir del epistolario como de la postura gregoriana frente al judaísmo en todo su corpus heurístico, en LAHAM COHEN 2013. 


\section{Antecedentes legislativos}

Como anticipamos, Gregorio no fue el primero - ni el último- en intentar interdecir la posesión judía de esclavos cristianos. Comencemos, entonces, por el Codex Theodosianus, el cual poseía un capítulo entero dedicado a la temática: Ne christianum mancipium Iudaeos habeat. La norma más tardía de tal sección respecto del tema prohibía la adquisición de esclavos cristianos (C.Th. XVI, 9, 5 del 423), pero otras, previas, habían garantizado su posesión siempre y cuando se respetase la religión de los mancipia (C.Th. XVI, 9, 3 del 415 y XVI, 9, 4 del 417). C.Th. XVI, 9, 1 del 335 había establecido que, en caso de que un no judío fuera circuncidado por su dueño, este recibiera la pena capital y aquel la libertad (C.Th. XVI, 8, 26 del 423, más benigna, establecía la confiscación y el exilio perpetuo). C.Th. XVI, 9, 2, otra ley temprana - del 329 o $339^{5}$ - había prohibido la compra de esclavos no judíos por parte de miembros de tal religión; caso contrario, el servus era reclamado por el fisco. ${ }^{6}$

Con el Codex producido en tiempos de Justiniano, las posibilidades de los judíos de conservar esclavos se reducirán, al menos en el plano legal y sobre todo para Oriente. ${ }^{7}$ Así, C.I. 1, 10, 1 estipuló la liberación de cualquier esclavo que fuera circuncidado y C.I. 1, 10, 2 prohibió de plano la posesión de esclavos cristianos estableciendo, de hecho, una multa a los judíos que fueran encontrados en tal situación. C.I. 1, 3, 54 fue más allá e impidió, a los neoconversos provenientes del judaísmo, recuperar a los servi ya liberados que habían adoptado el cristianismo antes que ellos. No debemos sobreestimar, sin embargo, el conocimiento y la aplicación de la ley por parte de los actores sociales: en muchos casos la norma era desconocida o burlada. Por otra parte, si bien Gregorio da cuenta de conocer la obra legislativa justinianea, esta tuvo un impacto limitado en Occidente.

En cuanto a la legislación eclesiástica, son particularmente útiles, por cercanía espacial y temporal, los cánones galos del siglo VI. Empecemos por el Concilio de Clermont, celebrado en el 535 que incluía una referencia a la problemática de la po-

5 La datación de esta norma es difícil, por lo que los investigadores han oscilado entre las dos fechas referidas.

6 Un análisis particular de las normas referidas a judíos en Linder 1987. Los extractos del Codex Theodosianus se encuentran expuestos, en base a la edición de Mommsen, en J. Rougé - R. Delmaire, Les lois religieuses des empereurs romains de Constantin a Théodose II (312-438), Paris, 2005. Para un panorama general sobre los judíos en el C.Th. véanse, entre otros, a De Bonfils 1992 y Nemo-Pekelman 2010. Clásico pero aún útil, JUSTER 1914. En general sobre la esclavitud en el período tardoantiguo, HARPER 2011. Vale la pena recordar que Antonino Pío y Septimio Severo habían prohibido a los judíos circuncidar a sus esclavos. Antes, Adriano había interdicto la circuncisión en general, pero ello debe ser interpretado como una respuesta a la rebelión de Bar Kojba. Véase a STERN 1976, II, 622-625, principalmente sus análisis en torno a Scriptores Historiae Augustae, Antoninus Pius, 5, 4 y Septimius Severus, 17, 1. Paradójicamente, la ley establecida por Antonino Pío fue retomada en el Codex Theodosianus pero con una modificación que la hacía más benigna dado que no incluía la pena de muerte para el judío implicado (C.Th. XVI, 9, 1). No obstante, C.Th. XVI, 9 , 2, promulgada cuatro años más tarde si nos adherimos a la datación más tardía, restableció la pena capital.

7 Los extractos del código de Justiniano pueden hallarse en la edición de P. Krueger, Codex Iustinianus, Kelp, 1998. Un análisis particular de las normas referidas a judíos en LiNDER 1987 y en RABELLo 2006. En general sobre los judíos en el período de Justiniano, sigue siendo valioso Rabello 1987-1988. 
sesión de esclavos cristianos por parte de judíos. ${ }^{8}$ El canon 14 se aproximaba a las primeras leyes teodosianas que permitían la posesión siempre y cuando se respetara la religión del esclavo (C.Th. XVI, 9, 3 y XVI, 9, 4). No obstante, también abría la posibilidad de escape ante el maltrato. La norma es, además, algo opaca. El texto, traducido llanamente, se muestra ambiguo y aparenta estipular que, en caso de que el esclavo fugara por segunda vez, el dueño judío debía pagar nuevamente su precio. ${ }^{9}$ Sin embargo, cánones posteriores establecieron el pago de una indemnización al dueño, por lo que algunas traducciones optaron por otra lectura en la cual el precio justo debía ser pagado al judío, hecho que es coherente con la legislación teodosiana previa y la conciliar posterior. ${ }^{10}$

El Cuarto Concilio de Orleans, ya en 541, volverá sobre el tema de los esclavos pero con mayor precisión. En este caso se establecerá con claridad que el judío al cual se le sustrajera el cristiano debía recibir una indemnización, ${ }^{11}$ en un claro contraste con lo establecido en Oriente por el Codex Iustinianus (C.I. 1, 10, 2), donde los judíos debían afrontar una multa además de la pérdida de su servus. Las posibilidades dadas al esclavo se ampliaban, en el caso de esta norma conciliar, dado que no solo podía buscar refugio en las iglesias sino también apelando a cualquier cristiano. El canon 31 del mismo concilio apunta a uno de los temores que subyacía tras las continuas prohibiciones a la tenencia de esclavos: la posibilidad de que estos fueran convertidos al judaísmo. Dada la importancia de esta norma, lo desarrollaremos en profundidad más adelante.

Siete años antes de que Gregorio asumiera el episcopado se celebró en Mâcon un concilio que poseía seis cánones referidos a judíos. Entre ellos también aparece la temática de los esclavos. El canon 16 demuestra la resistencia de los judíos a desprenderse de estos, incluso contra el pago de una indemnización. Se establece, entonces, la obligatoriedad de entregar al mancipium cuando fuera redimido por un particular a cambio de una indemnización que constaba de una suma fija -12 sólidos-. Como bien resaltó Walter Pakter, tal cifra era menor a la del mercado y, en contraposición al "justo precio" estipulado en los concilios tercero y cuarto de Orleans, representaba un empeoramiento de las posibilidades de los judíos de mantener a sus esclavos. ${ }^{12}$ Además, el servus ya no era liberado, sino que pasaba al control del cristiano que pagaba la indemnización. ${ }^{13}$ Por otra parte, la mera posesión permitía la sustracción

8 Tomamos el texto latino de los cánones a partir de la edición de C. Clercq, Concilia Galliae a. 511-695 (=CCSL 148A), Turnhout, 1963.

9 ...nullatenus a sacerdote reddantur, nisi praecium offeratur hac detur, quod mancipia ipsa valere pronunciaverit iusta taxation. Es el criterio seguido por LINDER $(1997,417)$, apegado al texto, más allá de la incoherencia respecto de normas previas y posteriores. De hecho, el autor aclara que probablemente la norma intentara indicar la necesidad de indemnizar al hebreo.

10 Así, aunque forzando el texto, PAKTER $(1988,89)$ optó por otra traducción. La cuestión, sin embargo, no se resuelve con ello. La traducción de PeLLegrini $(2010,143)$ mantiene la ambigüedad. El tema fue bien tratado por De BonfILS 1995.

11 C. 30.

12 PAKter 1988, 90.

13 Podemos sospechar, sin embargo, qué vinculo se generaba cuando, como establecía el Cuarto Concilio de Orleans, un cristiano "liberaba", pagando, a un esclavo en manos de judíos. De hecho, la liberación, tal vez, era concebida como la liberación del yugo judío y no como la pérdida del carácter de esclavo. 
del esclavo, sin necesidad de que este hubiera sido inducido al judaísmo o maltratado como convenía el Tercer Concilio de Orleans. Estas condiciones habrían fomentado la liberación de esclavos cristianos por parte de hombres de la misma religión que accederían a un servus a un precio económico. El canon 17, a su vez, insistía en punir el proselitismo ejercido sobre los esclavos cristianos en manos de hebreos, estableciendo la pérdida del mancipium y una pena no aclarada.

Cerrando con el ciclo de concilios del siglo VI - pero adentrándonos en territorio hispano- aparece el Tercer Concilio de Toledo del 589, donde vuelve a repetirse la prohibición. ${ }^{14}$ La interdicción, sin embargo, parece habilitar la compra-venta de esclavos cristianos dado que aclara que se aplica en los casos en los cuales el judío los obtuviera para utilizarlos in usus proprios. Ciertamente la ley no es clara y podría haber sido extendida al comercio.

Hasta aquí, los antecedentes legislativos. Gregorio conocía la normativa, tanto la teodosiana como la justinianea, ya que en diversas epístolas copia, textualmente, leyes. No conocemos, sin embargo, qué nivel de conocimiento tenía de la legislación eclesiástica gala o visigoda. Veamos, ahora, cómo lidió con las variadas situaciones en las cuales detectó a judíos que poseían esclavos.

\section{Escenarios múltiples y estrategias dispares}

Si bien Gregorio consideraba que todos los hombres eran iguales por naturaleza, afirmaba que Dios, mediante un designio oculto, había establecido jerarquías que debían ser sostenidas y respetadas. ${ }^{15}$ De hecho, el Papado contaba con esclavos propios. Podía adir, donar o comprarlos. ${ }^{16}$ No debemos perder de vista, entonces, que el Papa, acorde a sus tiempos, no rechazó la institución de la esclavitud. ${ }^{17}$ Ahora bien, cuando el esclavo en cuestión -pagano o cristiano- se encontraba bajo el control de un judío, Gregorio reaccionaba. No es casual que más de un tercio de las 26 epístolas gregorianas referidas a judíos traten el tema.

14 C. 14: Suggerente concilio id gloriosissimus domnus noster canonibus inserendum praecepit, ut Iudaeis non liceat Christianas habere uxores uel concubinas neque mancipium Christianum in usus proprios comparare; set et si qui filii ex tali coniugio nati sunt, assummendos esse ad baptisma, ("Con la sugerencia del concilio, nuestro gloriosísimo señor ordenó que sea insertada en los cánones, [la norma que] no permite a los judíos tener esposas o concubinas cristianas ni comprar un esclavo cristiano para uso propio; pero el niño que ha nacido de tales uniones debe ser llevado al bautismo", la cursiva es nuestra; texto latino tomado de la edición de G. Martínez Diez - F. Rodríguez, La colección canónica hispana, Madrid, 1992, 5).

15 Un pasaje de los Moralia deja en claro la posición gregoriana. Gregorio Magno, Moralia in Iob, XXI, 14, 22, 12-14: Nam, ut praefati sumus, omnes homines natura aequales genuit, sed variante meritorum ordine, alios aliis dispensatio occulta postponit ("Pues, como hemos dicho, el nacimiento hace a todos los hombres iguales pero, a través de una variación del orden de los méritos, una gestión oculta pone a unos detrás de otros"). Texto latino tomado de la edición de M. Adriaen, Gregorius Magnus. Moralia in Iob (=CCSL 143, 143 A y 143 B), Turnhout, 1979-1985. 593].

16 Un ejemplo de donación de esclavos por parte del Papado en Gregorio Magno, Registrum, III, 18 [julio,

17 En esta línea, SERFASs 2006. 
Lo que preocupaba principalmente al obispo de Roma no era que los judíos comerciaran con esclavos sino que los retuvieran. ${ }^{18}$ En efecto, se mostró flexible frente a las necesidades de los comerciantes judíos de esclavos, garantizando el negocio pero impidiendo que los servi adquiridos permanecieran en manos de aquellos. Un buen ejemplo es la carta IX, 105, del año 599, escrita al obispo de Nápoles, quien había intentado impedir que ciertos comerciantes judíos que habían ido a la Galia a comprar mancipia, continuaran con su actividad. Decía Gregorio:

Por consiguiente, que vuestra fraternidad, alerta y con preocupación, provea para que sea observado y cuidado lo siguiente: que cuando [los comerciantes judíos] retornan de la mencionada provincia [Galia], los esclavos cristianos que fueron acarreados por ellos sean entregados a aquellos que dieron la orden o bien sean vendidos a compradores cristianos en el plazo de cuarenta días. Traspuesto tal número de días, ninguno [de los esclavos] permanezca, en modo alguno, en manos de ellos [los judíos]. ${ }^{19}$

La continuidad de la actividad económica era garantizada, también, con otras medidas:

$\mathrm{Si}$, en cambio, algunos de los esclavos sufrieran una enfermedad tal que no pudieran ser vendidos en los días estatuidos, debe ser dispuesto, con toda precaución, que cuando hubieren recuperado la salud prístina, sean vendidos del mismo modo, porque no conviene que se invoque, generando daño, un asunto en el que se carece de culpa. Puesto que, en verdad, cuando algo nuevo se estatuye, la forma suele imponerse en el futuro de modo que la penalidad no condene lo hecho en el pasado, si permanecieran junto a ellos esclavos de la compra de años previos, o si recientemente [algunos esclavos cristianos] hubieran sido tomados por vos, tienen [los judíos] permiso para venderlos, mientras [los esclavos] estén con vos, de modo que no sean dañados, ignorantes antes de la prohibición, por esto que ellos mantenían como apropiado y luego fue prohibido. ${ }^{20}$

La preocupación del Papa era asegurar la provisión de esclavos a Italia -en este caso a Nápoles- incluso si esta involucraba a los judíos como intermediarios. El contexto de la Península Itálica lo ameritaba. La combinación de guerras, pestes, des-

18 En torno a la compra de esclavos, si bien generados en el mundo babilónico, existen múltiples responsa de tiempos gueónicos (ss. VI al XI aprox.) que ponen de relieve la práctica. Un buen análisis de este tema en WACHOLDER 1956.

19 Gregorio Magno, Registrum, IX, 105 [febrero, 599] 12-17: Proinde fraternitas uestra hoc uigilanti sollicitudine obseruari ac custodiri prouideat, ut reuertentibus eis de praefata prouincia christiana mancipia, quae ab ipsis adduci contigerit, aut mandatoribus contradantur aut certe christianis emptoribus intra diem quadragesimum uenumdentur. Et transacto hoc dierum numero nullum apud eo quolibet modo remaneant.

20 Id., 17-28: Si autem quaedam ex eisdem mancipiis talem aegritudinem fortassis incurrerint, ut intra statutos dies uendi non ualeant, adhibenda sollicitudo est, ut, dum saluti fuerint pristinae restituta, similiter modis omnibus distrahantur, quia rem quae culpa caret ad damnum uocari non conuenit. Quoniam uero, quotiens nouum quid statuitur, ita solet futuris formam imponere, ut multa dispendiis praeterita non condemnet, si qua apud eos mancipia de emptione anni praeteriti remanserunt uel a uobis nuper ablata sunt, dum apud uos sunt posita, ea habent alienandi licentiam, ne detrimentum ante prohibitionem possint ignorantes incurrere, quod eos postmodum dignum est uetitos sustinere. 
plazamientos y hambrunas, había generado una seria falta de brazos en el campo. ${ }^{21}$ Gregorio, entonces, toleraba que aquellos que, en su lógica -expresada claramente en sus obras de tinte teológico- ${ }^{22}$ habían rechazado a Dios y habían sido castigados y subordinados por Este, compraran y subordinaran temporalmente a quienes sí lo habían aceptado.

Pero el objetivo de este artículo no está en analizar el posicionamiento de Gregorio frente al comercio de esclavos. Aspiramos, en efecto, a comprender las razones de su preocupación en torno a la posesión de estos. Un buen punto de partida para investigar esta situación es la epístola IV, 21, escrita al obispo de Luni, ciudad de la Liguria. Afirma Gregorio:

Ha llegado a nosotros, a través de la declaración de muchos, que hay esclavos cristianos retenidos en la servidumbre por judíos que habitan en la ciudad de Luni. Tal hecho nos ha parecido aún más penoso a causa de la tolerancia de tu fraternidad en el asunto. Ciertamente, correspondía -en relación a tu posición y en consideración de la religión cristiana- no dejar, en ninguna ocasión, que las almas de los simples sirvieran a la superstición judaica, no tanto a través de la persuasión sino a partir de la ley. Por tal razón, exhortamos a tu fraternidad a que, acorde a las más pías leyes transmitidas, ningún judío pueda retener en su posesión a un esclavo cristiano. Si alguno fuera hallado en poder de ellos, cuida que la libertad sea asegurada mediante el auxilio de la sanción de las leyes. ${ }^{23}$

Hasta aquí, el planteamiento es claro y se encuentra en consonancia con la legislación previa. Quienes pertenecen a la superstitio judía no pueden poseer esclavos cristianos. No solo la persuasión debe ser utilizada sino, principalmente, la potestas. La comunicación pone de relieve, también, la connivencia de las autoridades locales con los judíos, tema sobre el que volveremos más adelante. Gregorio presenta, a continuación, dos tipos de protocolos a seguir:

Aunque, ciertamente, estos [los esclavos cristianos] que están en las posesiones de aquellos [los judíos] son también -según la severidad de las leyes- libres, dado que

21 En esta línea, son válidas las precisas palabras de Silvia ACERBI $(2006,86)$ sobre la situación en la Península Itálica en tiempos de Gregorio: "Del Registrum emerge otro de los aspectos más duraderos de esta crisis demográfica: la falta de brazos para la agricultura. Gregorio ha sabido que algunos reclutadores imperiales, los scribones, han llegado a Sicilia en búsqueda de nuevos soldados entre los campesinos [...] El temor del pontífice, comunicado al subdiácono Petrus junto a la petición de intervenir oportunamente, es que los campesinos, cuyo número está disminuyendo netamente y que cada vez son más difíciles de sustituir, se alejen de las grandes propiedades provocando su ruina". Para un panorama general, véase a CRACCO RUGGINI 1995.

22 Remitimos, sobre este tema, a la nota 43.

23 Gregorio Magno, Registrum, IV, 21 [mayo, 594] 2-12: Multorum ad nos relatione peruenit a Iudaeis in Lunensi ciuitate degentibus in seruitium Christiana detineri mancipia. Quae res nobis tanto uisa est asperior, quanto eam fraternitatis tuae patientia operabatur. Oportebat quippe te respectu loci tui atque christianae religionis intuitu nullam relinquere occasionem, ut superstitioni Iudaicae simplices animae non tam suasionibus quam potestatis iure quodammodo deseruirent. Quamobrem hortamur fraternitatem tuam ut, secundum piissimarum legum tramitem, nulli Iudaeo liceat Christianum mancipium in suo retinere dominio. Sed si qui penes eos inueniuntur, libertas eis tuitionis auxilio ex legum sanctione seruetur. 
han estado adheridos a las tierras de ellos cultivándolas por largo tiempo y están obligados por los acuerdos del lugar; permanezcan cultivando los campos como habían acostumbrado, suministren los pagos a los hombres mencionados [los terratenientes judíos] y realicen todas las actividades de colonos y originarios que las leyes ordenan. Que a ellos [los esclavos/colonos cristianos] no sea fijada ninguna carga extra. Si alguno de aquellos [los judíos] deseara mover hacia otro lugar a uno de estos o retenerlo en su servicio [obsequium], que considere para sí mismo que quien [desecha] la ley de los colonos con su temeridad, desechó, para sí, la ley de dominio. ${ }^{24}$

Gregorio pretende, entonces, que los cristianos que labran la tierra de los judíos permanezcan realizando tal actividad, ahora en calidad de colonos. Pueden ser colonos de los judíos, pero no esclavos. Deben continuar adscritos a la tierra y sujetos a la misma normativa que se aplicaba a cualquier terrateniente. La explicación de esta diferenciación responde a tres razones. En primer lugar, como afirmaremos luego, la imperativa liberación de aquellos esclavos que trabajaban en un grado de fuerte control por parte de los hebreos es producto del temor a la conversión dado que existía una tendencia judía a convertir a los servi. El contacto entre terrateniente y colono (o, incluso, con un esclavo rural) ${ }^{25}$ tenía, en principio, un nivel de asiduidad menor $\mathrm{y}$, por ende, los riesgos para la religión del labrador serían escasos. Es en tal sentido que Adam Serfass habla de distinction of proximity en relación a las dos actitudes gregorianas que se desprenden de la misiva. ${ }^{26}$ El temor a la conversión se revela, también, en la explícita afirmación gregoriana referida a evitar la imposición de cargas adicionales a los colonos cristianos. Bien conocía Gregorio que el aumento o la retracción de los onera podía operar como un mecanismo para incentivar procesos de conversión. De hecho, él mismo había elevado la carga a los coloni paganos que rechazaban la conversión al cristianismo y había prometido reducirla a los colonos judíos que pasaran a la fe mayoritaria. ${ }^{27}$

La segunda causa versa sobre el aspecto religioso. Aunque en términos reales las distinciones jurídicas no implicaban cambios en el vínculo entre explotadores y explotados, para Gregorio era repudiable que un cristiano fuera esclavo de un judío a diferencia de un colono, quien era -cuanto menos nominalmente- libre. Esta razón

24 Id., 12-21: Hi uero qui in possessionibus eorum sunt, licet et ipsi ex legum districtione sint liberi, tamen quia colendis terris eorum diutius adhaeserunt, utpote condicionem loci debentes, ad colenda quae consueuerant rura permaneant, pensiones praedictis uiris praebeant, cuncta quae de colonis uel originariis iura praecipiunt peragant. Nihil eis extra haec oneris amplius indicatur. Quod si quis quemquam de his uel ad alium migrare locum uel in obsequium suum retinere uoluerit, ipse sibi reputet, qui ius colonarium temeritate sua, ius uero dominii sibi iuris seueritate damnauit.

25 La distinción entre esclavo y colono dista de ser precisa en el período. Sobre el particular, véase a VERA 1986 y 1998. Véase también ACERBi 2006, 85-113. En palabras de la autora: “... de las páginas del Epistolario gregoriano emerge que el esclavo agrícola es, desde una óptica funcional, más colonus que servus" (ACERBI 2006, 111).

26 SERFASS 2006, 101: "It is a distinction of proximity: those most susceptible to their masters' influence must be freed; those less susceptible may be accommodated in more creative ways".

27 Sobre la instrucción de aumentar a los coloni paganos las cargas que pagaban, véase Gregorio Magno, Registrum, IV, 26 [mayo, 594]. Sobre la promesa de rebajar los onera a los colonos judíos que se convirtieran al cristianismo, Id., II, 50 [julio-agosto, 592] y V, 7 [octubre, 594]. Nótese que, frente a paganos, se castiga la permanencia en su religiosidad mientras que, ante judíos, se premia el pasaje al cristianismo. 
habrá tenido peso pero no debemos sobredimensionarla. Al permitir la existencia de coloni cristianos bajo control judío, el Papa aceptó que un cristiano -aunque de modo regulado- estuviera subordinado a sujetos que, en el plano de su propia teología, se encontraban subordinados a los cristianos.

La tercera causa se centra en el aspecto socioeconómico. La necesidad de evitar trastornos en la campiña impulsó a Gregorio, en línea con la situación ya observada con los traficantes de esclavos, a soportar esta inversión de roles, incluso contra sus propias palabras. El Papa no deseaba agravar la situación, sobre todo en la Liguria, donde el dominio bizantino era precario y la amenaza longobarda, latente. Si concedemos que los terratenientes judíos citados ocupaban una posición de relativa importancia en la estructura productiva, podemos comprender la razón de la cautela del obispo.

Volvamos, por un instante, a la epístola IX, 105. En dicha comunicación Gregorio afirmaba que, con el fin de conservar a sus esclavos -suponemos, personales- un judío llamado Basilio aspiraba a donarlos a sus hijos ya convertidos al cristianismo para poder seguir haciendo uso de ellos sin correr peligro de perderlos. Estamos, entonces, ante uno de los casos en los cuales el entorpecimiento de las actividades económicas de los judíos pudo haber estimulado la conversión hacia el cristianismo. Decía Gregorio:

Nos han dado a conocer, además, que el mentado Basilio desea conceder ciertos esclavos -a título de donación- a sus hijos, quienes por el favor de Dios son cristianos, con el fin de retenerlos y, a través de tal circunstancia, que lo sirvan, habiendo sido sustraído solo el título de señor. Después de esto, [los esclavos] que quisieran, tal vez, refugiarse en la Iglesia de modo que debieran devenir cristianos, no podrán ser reclamados en la libertad sino en el dominio de ellos [los hijos de Basilio] a quienes habían sido donados de antemano. ${ }^{28}$

De la misiva se desprende -volveremos a verlo en otra epístola, en breve- que era una práctica habitual -0 , cuanto menos, conocida- que los esclavos escaparan de sus posesores judíos. Como ya hemos resaltado, tanto el Codex Theodosianus como diversos cánones galos del s. VI habían establecido el derecho a fugarse del control judío. Gregorio cree hallar un artificio orientado a conservar los esclavos -eludiendo el riesgo al escape- sin renunciar a la religión.

Las estrategias desplegadas para mantener el control sobre los mancipia eran variadas. Tal como ya señalamos, el Codex de Justiniano prohibía, en 1, 3, 54, recuperar, tras la conversión al cristianismo por parte de un judío, los esclavos que había poseído y perdido precisamente por ser hebreo. ${ }^{29}$ En esta línea, una epístola de Gregorio

28 Gregorio Magno, Registrum, IX, 105 [febrero, 599] 29-35: Nuntiatum praeterea nobis est suprascriptum Basilium filiis suis Deo propitio christianis quaedam mancipia ad hoc uelle titulo donationis concedere, ut ei huius occasionis obtentu, domini solummodo nomine ablato, deseruiant et post hoc, si ad ecclesiam confugiendum forte crediderint, ut fieri debeant christiana, non in libertate sed eorum dominio, quibus ante donata sunt, uindicentur.

${ }_{29}$ C.I., I, 3, 54 fue promulgada, para el África reconquistada, probablemente entre el 534 y el 535. La ley involucra varios aspectos. En cuanto al asunto que nos atañe aquí, afirma: Quod si forte posthac etiam 
hace constar que el hijo de un samaritano, convertido al cristianismo, reclamaba al ex esclavo de su padre, quien había sido liberado por el obispo local, a causa de la religión de su anterior dueño jurídico. La acción fue repudiada por Gregorio, quien refería directamente a la citada norma del Código de Justiniano. ${ }^{30}$

Retornando al caso de Basilio, es pertinente remarcar que la preocupación inmediata de Gregorio recaía, entendemos, en el peligro de conversión de los esclavos que permanecerían, bajo la artimaña, en poder de Basilio. En virtud de ello, exigía al obispo local que estuviera atento a la situación y se asegurara que los esclavos in domo eius [de Basilio] non maneant. ${ }^{31}$ Volvemos, aquí, a la lógica observada en la epístola enviada a Luni en la que se permitía la posesión de colonos cristianos mientras se rechazaba que los esclavos estuvieran bajo control directo de los judíos, hecho que refería, probablemente, a su presencia en el hogar.

Otra situación donde la problemática de los esclavos en manos de judíos recibe un trato a partir del cual Gregorio fomenta el pasaje al cristianismo nos lleva nuevamente a Nápoles. Escribe Gregorio en el 596:

Hemos escrito a tu fraternidad, tiempo atrás, ${ }^{32}$ para que estos que, con la voluntad de Dios, desearan venir desde la superstición judía a la fe cristiana, no puedan ser vendidos de ningún modo por sus señores; más bien, desde que manifestaran el deseo de su voluntad, deberían ser protegidos en la libertad en todo aspecto. ${ }^{33}$

Estamos ante una medida activa, a diferencia del resto de las acciones en torno a los esclavos en las cuales el objetivo prioritario era evitar posibles influencias judaizantes en ellos. Cierto es, como vimos, que la dificultad de poseer servi conllevaba

ipsi domini eorum ad orthodoxam fidem conversi fuerint, non liceat eis ad servitutem reducere illos, qui eos ad fidem orthodoxam praecesserunt: sed si quis talia usurpaverit, poenis gravissimis subiacebit ("Si, tal vez, después de esto [la conversión al cristianismo de esclavos judíos y paganos, con la subsecuente liberación de estos] los mismos señores de ellos [se refiere a los dueños de esclavos judíos] se convirtieran a la fe ortodoxa, no les sea permitido [nuevamente] reducir a aquellos, quienes los precedieron en la fe católica, a la servidumbre. Pero si alguno así lo hiciera, sufrirá penas gravísimas").

30 Gregorio Magno, Registrum, VIII, 21 [mayo, 598] 14-19: ...et a nullo sub qualibet occasione grauari permittat, quia, dum superstitiosae sectae mancipia dominos suos ad fidem praecedentia seruitio eorum aperte redigi iura prohibeant, quanto magis hic de christianis parentibus natus et pactus de paruulo Christianus hanc non debet quaestionem aliquo modo sustinere... ("Y no permitas que bajo ninguna circunstancia sea oprimido [se refiere al ex esclavo] por nadie, dado que, si la leyes prohíben abiertamente que los esclavos de una secta supersticiosa que abrazaron la fe antes que los señores a los que servían sean reducidos [nuevamente a la esclavitud] ¿cuánto más este, nacido de padres cristianos y hecho cristiano de pequeño, no debe sufrir cuestionamiento de ningún tipo?"; la cursiva es nuestra). Nótese la similitud entre lo afirmado por Gregorio y la ley recientemente citada, hecho que confirma, una vez más, el conocimiento gregoriano de ambos cuerpos legislativos.

31 Gregorio Magno, Registrum, IX, 105 [febrero, 599] 37-38: "Y que no permanezcan en la casa de él [de Basilio]".

32 Gregorio refiere a una carta que no se ha conservado.

33 Gregorio Magno, Registrum, VI, 29 [abril, 596] 2-6: Fraternitati uestrae ante hoc tempus scripsimus ut hos qui de Iudaica superstitione ad christianam fidem Deo aspirante uenire desiderant dominis eorum nulla esset licentia uenundandi, sed ex eo uoluntatis suae desiderium prodidissent, et defendi in libertatem per omnia debuissent. Si bien en este pasaje no se explicita que se trate de posesores judíos, la carta lo aclara, como se verá en breve, más adelante. 
indirectamente a conversiones de judíos, pero la principal preocupación gregoriana era evitar el pasaje de cristianos hacia el judaísmo. En este caso, sin embargo, no hay ningún riesgo para el cristianismo: el esclavo es judío. Se trata, claramente, de una decisión tendente a estimular el paso de individuos desde el judaísmo hacia el cristianismo.

Gregorio, con su epístola, da un paso más en la motivación a la conversión al cristianismo. Más aún, la imposibilidad de vender a aquellos que decidieran abrazar la fe de Cristo está orientada a garantizar la libertad de los implicados, dado que una venta mantendría en la esclavitud al converso y disminuiría el incentivo a cambiar de religión. Seguramente Gregorio podría haber dudado de la sinceridad de las conversiones, pero, al igual que en el caso de los coloni, habrá considerado un triunfo, cuanto menos en el mediano plazo, el pasaje de tales individuos a la religión mayoritaria. ${ }^{34}$

La norma se hace extensiva, también, a los paganos, con quienes los judíos, dice Gregorio, no aplicaban la legislación:

Pero dado que, según conocimos, no sabiendo pensar con discreción y sutileza en nuestra voluntad ni en los estatutos de la ley, [los judíos] consideran que esta condición no es aplicada a los esclavos paganos, es necesario que tu fraternidad esté preocupada. Y si, desde el servicio de ellos [de los judíos] no solo un judío sino también cualquier pagano, deseara hacerse cristiano, bajo ningún artificio o argumento de cualquier judío exista facultad para venderlo después de que su voluntad fuera revelada. Que quien desea ser convertido a la fe cristiana sea reivindicado en la libertad, en todos los aspectos, a través de tu defensa. ${ }^{35}$

Gregorio se muestra moderado. Relativiza la mala voluntad de los hebreos, adscribiéndoles desconocimiento o interpretación errónea de la ley cuando, según hemos visto, toda la legislación previa prohibía la posesión de esclavos cristianos -incluso recientemente convertidos- más allá de su origen. Es posible, sin embargo, que el uso de cada región -recordemos que la extensión de la aplicación de la normativa era dispar- fuera diferente. Como veremos, incluso las autoridades desconocían o hacían caso omiso a determinadas directivas legales. Debe remarcarse, también, que Gregorio se acerca más, en este caso, a la normativa de Justiniano que a los cánones galos, dado que elimina la figura de una indemnización por la sustracción del servus. Respecto del Codex Theodosianus, parece estar más lejos pero, recordemos, las varias leyes referidas a la temática en tal corpus no eran coherentes entre sí y su lectura dejaba espacio a interpretaciones personales.

\footnotetext{
34 Había afirmado, cuando instaba a rebajar el canon que pagaban los coloni judíos en tierras eclesiásticas: Aut ipsos ergo aut eorum filios lucramur. Non est graue, quicquid de pensione pro Christo dimittimus ("Por consiguiente, o bien los ganamos a ellos mismos, o bien ganamos a sus hijos. No es grave que renunciemos, en favor de Cristo, a cierta parte del ingreso"). Gregorio Magno, Registrum, V, 7 [octubre, 594] 19-23.

35 Gregorio Magno, Registrum, VI, 29 [abril, 596] 6-15: Sed quia, quantum cognouimus, nec uoluntatem nostram nec legum statuta subtili scientes discretione pensare, in paganis seruis hac se non arbitrantur condicione constringi, fraternitatem uestram oportet esse sollicitam. Et si de eorum seruitio non solum Iudaeus sed etiam quisquam paganorum fieri uoluerit Christianus, postquam uoluntas eius fuerit patefacta, nec hunc sub quolibet ingenio uel argumento cuipiam Iudaeorum uenundandi facultas sit, sed is qui ad christianam conuerti fidem desiderat defensione uestra in libertatem modis omnibus uindicetur.
} 
Debemos resaltar que, en las epístolas dirigidas a comerciantes y a terratenientes judíos, el Papa no presentó ningún mecanismo para atraerlos al cristianismo, más allá de la gradual prédica. En cambio, en los casos de coloni y servi que hemos visto, sí puso al descubierto no solo la intención de convertirlos sino también las herramientas para llevar a cabo la acción. Tal conducta se relaciona -ya lo hemos anticipado-con el criterio gregoriano de no sumar inconvenientes en la estructura productiva itálica. Las consecuencias políticas, sociales y económicas de presionar y convertir a terratenientes o a comerciantes importantes eran sin duda mayores que las que se generaban con una política agresiva frente a colonos o esclavos judíos, por lo que el obispo de Roma enfatizó la necesidad de convertir a estos últimos dos grupos, más vulnerables y con menor capacidad de reacción. Utilizó, además, estímulos económicos y evitó medidas coactivas.

Siguiendo con las epístolas sobre el tema aquí analizado, el pasaje que abre este trabajo refiere a un judío, llamado Nasas, que poseía -en Sicilia- esclavos cristianos. En tal misiva Gregorio apelaba, nuevamente, a la ley como argumento. Refería, además, a la contaminación, término que implica una fuerte toma de posición. Toda la carta, de hecho, está teñida de un lenguaje verdaderamente hostil hacia el judaísmo. Pero la causa principal de la indignación del obispo de Roma es, en este caso, que Nasas había erigido un altar, en nombre de Elías, al cual asistían cristianos. ${ }^{36}$ No es este el espacio, sin embargo, para discutir qué tipo de culto se llevaba a cabo allí.

En Narbona, bajo control visigodo, el Papa también detectó presencia de esclavos cristianos en manos de judíos. En este caso instruyó a Cándido, rector del patrimonio galo, para que gestionara la liberación de cuatro esclavos. La misiva, corta, pone de manifiesto el conocimiento gregoriano de sus propias limitaciones a la hora de actuar en un territorio fuera de su control. La instrucción dada, recordemos, al rector del patrimonio galo y no a un funcionario visigodo, reza:

Y dado que es grave y execrable que los cristianos estén en el servicio de los judíos, exhortamos a tu dilección a que, mediante el presente escrito y con toda la sutileza y preocupación, se afane por investigar. Y en caso de que el asunto fuera así, y fuera evidente que estos no son redimidos, ni que el mencionado portador de la carta pudo hacerlo, con tu celo los redimas, sabiendo que, todo lo que dieras por ellos, sin dudas, será imputado en tus balances. ${ }^{37}$

Se pide al presbítero investigar cum omni subtilitate y se le encomienda actuar, en caso de que el portador de la misiva u otro implicado no pudiera lograr el cometido. El tono de la epístola es, efectivamente, moderado. No se exige acción inmediata sino que se la recomienda. Gregorio estimula a su interlocutor mencionándole los

36 Gregorio Magno, Registrum, III, 37 [mayo, 593].

37 Gregorio Magno, Registrum, VII, 21 [Mayo, 597] 4-11: Et quia omnino graue execrandumque est Christianos esse in seruitio Iudaeorum, dilectionem tuam scriptis praesentibus adhortamur ut cum omni subtilitate et sollicitudine studeat perscrutari. Et si re uera ita est atque manifesta tibi ueritate constiterit quia neque ipsi, unde se redimant, neque suprascriptus portitor habet, eos studii tui sit redimere, sciens quia, quicquid in eis dederis, tuis sine dubio rationibus imputatur. La expresión "imputar en los balances" es una referencia espiritual, no monetaria. 
beneficios para su alma pero no le exige resultados, dado que seguramente sabía que su campo de actuación era estrecho. Ernst Baltrusch consideraba que Gregorio sugería la compra de los esclavos, cuando, según la ley, debían haber sido liberados automáticamente. Para el autor aquí hay otra demostración de la tendencia gregoriana a interpretar la norma acorde a las necesidades. ${ }^{38}$ Tal decisión, insistimos, responde al conocimiento, por parte del Papa, de las costumbres y realidades de cada región.

También en el mundo visigodo, pero en una epístola enviada a Recaredo, son mencionados los judíos. Gregorio refiere a cierta ley que el monarca había promulgado contra aquellos, resistiendo, incluso, una oferta monetaria que los hebreos habían presentado para convencer al rey. ${ }^{39}$ La mayor parte de los autores acuerda con la idea de que se trataba de la prohibición de la posesión de esclavos promulgada en $L V$. XII, 2, 12 del $588^{40}$ y reafirmada en el Tercer Concilio de Toledo del 589. ${ }^{41}$ Debemos enfatizar, sin embargo, que se trata de una inferencia dado que si bien la mencionada ley fue promulgada por Recaredo, Gregorio pudo estar apuntando a las diversas políticas impulsadas en el mentado concilio, las cuales incluían el bautismo de los hijos de matrimonios mixtos y la prohibición del ejercicio de cargos públicos. Es cierto, no obstante, que el obispo de Roma refiere a una ley y es más verosímil la primera opción, sobre todo por la preocupación que le generaba la temática.

En otra región externa a la Península Itálica, en este caso la Galia merovingia, encontró el Papa a esclavos cristianos en manos de judíos. En este caso, su lenguaje es categórico:

Además estamos sorprendidos de que permitas, en tu reino, que los judíos posean esclavos cristianos. ¿Qué son, en efecto, todos los cristianos sino miembros de Cristo? Todos sabemos, claramente, que respetas lealmente a la cabeza de los miembros [a Cristo]. Pero juzgue su excelencia cuán contradictorio es honrar a la cabeza y permitir que los miembros de esta sean pisoteados por los enemigos. Por lo tanto, pedimos que un decreto de tu excelencia remueva estas malvadas perversiones de tu reino, de modo que ustedes se muestren ante el Dios omnipotente entre los más dignos adoradores suyos y liberen a los fieles de Él de sus enemigos. ${ }^{42}$

38 BALtrusCH 1994, 49

39 Gregorio Magno, Registrum, IX, 229 [agosto, 599] 51-57: Praeterea indico quia creuit de uestro opere in laudibus Dei hoc quod dilectissimo filio meo Probino presbitero narrante cognoui quia, cum uestra excelentia constitutionem quandam contra Iudaeorum perfidiam dedisset, hi de quibus prolata fuerat rectitudinem uestrae mentis inflectere pecuniarum summam offerendo moliti sunt. Quam excellentia uestra contempsit et omnipotentis Dei placere iudicio requirens auro innocentiam praetulit.

40 Así, entre otros, García Iglesias 1978, 105-106; Boesch Gajano 1979, 27; Rabello 1983-1984, 381. Es interesante resaltar que BACHRACH $(1977,38)$, sin evidencia heurística firme y a contrapelo de la mayoría de los estudiosos, creía ver en Recaredo a un monarca projudío. Sobre la situación de los judíos en la Hispania visigoda existe una gran cantidad de bibliografía. Dentro de los trabajos destinados a su análisis, algunos se han aproximado al problema de los esclavos cristianos en poder de judíos. Entre ellos, véase a JUSTER 1912; Albert 1976; González Salinero 1998; ID. 1999; ID. 2000; ID. 2012; Martin - Nemo-PeKelman 2008.

41 Para este canon remitimos a la nota 14.

42 Gregorio Magno, Registrum, IX, 214 [julio, 599] 74-83: Omnino praeterea admirati sumus ut in regno uestro Iudaeos christiana mancipia possidere permittis. Quid enim sunt Christiani omnes nisi membra Christi? Quorum uidelicet membrorum caput cuncti nouimus quia fideliter honoratis. Sed quam diuersum sit excellentia uestra perpendat, caput honorare et membra ipsius hostibus calcanda permittere. Atque ideo 
Los judíos son asimilados, explícitamente, a las figuras del hostis y del inimicus. El uso de estas palabras es llamativo. En otras epístolas -no así en otros tratados- ${ }^{43}$ Gregorio evitó referencias violentas al judaísmo. Por ejemplo, exigiendo concordia al obispo local, en Cagliari, llamó a los judíos simplemente habitatores. ${ }^{44}$ Ante un adversario tangible e inmediato como los longobardos, Gregorio instaba a la paz entre cristianos y judíos. Cuando se trataba de la posesión de esclavos cristianos, veía a los judíos como enemigos. Esta diversa ponderación es producto, claramente, del temor gregoriano a la conversión de los cristianos.

Pero no todos los hombres de Iglesia itálicos actuaban del mismo modo. Hacia el 593, en Cagliari, Gregorio encontró un tipo de praxis que le generó estupor. Escribió al obispo local:

También nos llegó [la noticia] de que los esclavos y esclavas de los judíos que, a causa de la fe, se refugian en las iglesias, o bien son restituidos a sus señores infieles, o bien se les otorga [a los judíos] un precio para que no sean restituidos. ${ }^{45}$

No solo en Galia existían autoridades religiosas y laicas que consentían la posesión de servi cristianos por parte de los judíos. Ante la fuga de los esclavos, las autoridades sardas -al parecer hombres de Iglesia dado que la huida se realizaba hacia las casas de culto- seguían dos caminos. En primer término, la simple devolución del esclavo a su dueño jurídico. Tal práctica, común cuando se trataba de dueños cristianos, podría

petimus ut excellentiae uestrae constitutio de regno suo huius prauitatis mala remoueat, ut in hoc uos amplius dignos cultores omnipotentis Domini demonstretis, quod fideles illius ab inimicis eius absoluitis. El mismo párrafo se encuentra en la epístola IX, 216, dado que la epístola aquí citada fue enviada a Brunegilda, regente de Teodeberto II y Teodorico II mientras que aquella tuvo como receptores a ambos jóvenes monarcas.

43 Ha llamado la atención de diversos investigadores el trato diferencial que reciben los judíos en el epistolario y en el resto de las obras gregorianas. Así, mientras que en las misivas se percibe una visión equilibrada, con un limitadísimo uso de topoi adversus Iudaeos, en textos como Moralia in Iob o In Canticum Canticorum el discurso antijudío adquiere relieve y entronca con una tradición adversus Iudaeos que ya arrastraba varios siglos. El fenómeno también se registra en su obra parenética: Homiliae in Hiezechihelem prophetam y Homiliae in Evangelia. La razón de esta disonancia se explica cuando analizamos el tipo de obra y el auditorio imaginado para cada una de ellas por Gregorio. Así, las epístolas, dirigidas a sujetos específicos, atienden a problemas particulares, sin recalar excesivamente en la teología. En ellas, el obispo de Roma resolvió problemáticas puntuales, asumiendo el rol de hombre de Estado y tendiendo a mantener el orden de la Península Itálica. En cambio, sus obras de tinte teológico se alinean con la tradición adversus Iudaeos. No hacerlo, de hecho, hubiese implicado una desviación respecto de la tradición. Si bien la virulencia discursiva frente a los judíos es menor que en autores como Juan Crisóstomo, Jerónimo o, incluso, Agustín, no representa novedad ni alteración del discurso previo. En la Regula pastoralis y en los Dialogi, textos en los cuales la teología ocupa un lugar secundario, la imagen de los judíos se desdibuja y, cuando aparece-sobre todo en los Dialogi- se presenta de un modo neutral, acercándose al registro del epistolario. El antijudaísmo gregoriano es, entonces, principalmente teológico. Dado que el análisis de estos aspectos implicaría un desmedido uso de espacio y se aleja de los objetivos de este artículo, nos limitamos a presentar la bibliografía pertinente: PARKES 1961 (1934), 210-221; Markus 1995; Cohen 1999, 73-94; Stern 2000; LaHam Cohen 2011; ID. 2013; ID. 2013a; ID. 2015; ID. 2015a; PÉGOLO - NOCE - LAHAM COHEN 2013.

44 Gregorio Magno, Registrum, IX, 196 [julio, 599]. Sobre los diversos calificativos utilizados por Gregorio en sus epístolas frente a los judíos, véase LAHAM COHEN 2008.

45 Gregorio Magno, Registrum, IV, 9 [septiembre, 593] 43-45: Peruenit etiam ad nos seruos ancillasque Iudaeorum fidei causa ad ecclesiam refugientes aut infidelibus restitui dominis, aut eorum ne restituantur pretium dari. 
haber sido justificada desde algunas normas del Codex Theodosianus (C.Th. XVI, 9, 1; XVI, 9, 3 y, parcialmente, XVI, 9, 4) que permitían la posesión, excepto en casos de circuncisión o imposición de la religión judía sobre los mancipia. Incluso los primeros cánones galos del siglo VI referidos a la temática se manifestaban en tal sentido, siendo la liberación garantizada solo en casos de maltrato. La segunda opción, rechazada por Gregorio Magno, era aquella de indemnizar al judío ante la fuga del cristiano. Como también hemos visto, los cánones tardíos de la Galia en el siglo VI estipulaban tal mecanismo ante el escape de un esclavo. Tampoco era necesaria, en la mencionada legislación, una causal para garantizar la liberación del servus cristiano.

Pero Gregorio exige otro tipo de política:

Te exhortamos, pues, a que no permitas que se mantenga - de ninguna manera - tan depravada costumbre. No debes permitir que ningún esclavo que se fugue hacia sitios venerables a causa de la fe, soporte, de ningún modo, perjuicio. Ya sea que haya sido cristiano desde hace mucho tiempo o haya sido bautizado en el presente, que sea defendida su libertad en todos los aspectos a través del religioso patrocinio de la piedad eclesiástica sin daño alguno a los pobres. ${ }^{46}$

El Papa se acerca, aquí, a la normativa de Justiniano, la cual negaba toda indemnización al judío y tampoco mencionaba la necesidad de justificar la fuga. Es un acercamiento parcial, dado que el Codex estipulaba una multa al judío en cuestión; sanción que, como vemos, no es siquiera sugerida. Es transparente, por otra parte, que Gregorio quiere dejar en claro que los neoconversos también están contemplados por la ley, hecho que potenciaría, como vimos, la conversión de esclavos de origen pagano o judío.

Desde el punto de vista del lenguaje utilizado aparece, aquí, el término infidelis para catalogar a los judíos. La mecánica se repite: el obispo de Roma necesita modificar una política hacia una mayor rigidez y, además de las órdenes emanadas, filtra un lenguaje que pone en evidencia el carácter negativo de los judíos con el fin de aumentar el efecto de la comunicación.

Lo central de la misiva, a nuestro entender, es la disparidad de criterios que existían entre diversos hombres de Iglesia. Aquí, Gregorio exige una política firme frente a los judíos; seis años más tarde el Papa recomendará la moderación ante la toma de la sinagoga de la misma ciudad. ${ }^{47}$ En el primer caso, son los clérigos de Cerdeña quienes protegen a los judíos; en el segundo, son ellos quienes aparecen como responsables, cuanto menos por omisión, del ataque a la sinagoga. La ausencia de una política sistemática frente a los colectivos judíos es una de las realidades que emergen del Registrum. El cuadro, así, conjuga integración y violencia. Cada epístola gregoriana muestra parte de ambas realidades.

\footnotetext{
46 Id., 45-51: Hortamur igitur ut nullatenus tam prauam consuetudinem manere permittas. Sed quilibet Iudaeorum seruus ad uenerabilia loca fidei causa confugerit, nullatenus eum patiamini praeiudicium sustinere. Sed siue olim Christianus, siue nunc fuerit baptizatus, sine ullo pauperum damno religioso ecclesiasticae pietatis patrocinio in libertatem modis omnibus defendatur.

47 Gregorio Magno, Registrum, IX, 196 [julio, 599].
} 
Ahora bien, ¿cómo explicar la preocupación de la legislación en general y de Gregorio en particular sobre la tenencia de esclavos cristianos por parte de judíos?

\section{Temores fundados}

Ciertos autores han considerado diversas posibilidades para explicar la preocupación del Papa en torno a los esclavos cristianos bajo control de judíos. Katz, por ejemplo, afirmó que Gregorio, simplemente, siguió la legislación imperante. Pero, como vimos, el obispo de Roma no se limitaba a la ciega repetición de la ley. Aunque conocía las reglas, las aplicaba según sus principios y, en general, acorde a las necesidades de la coyuntura. En virtud de ello, deben ser rastreadas otras motivaciones.

Ya hemos referido a cuestiones de índole simbólica. En la lógica de los Padres de Iglesia, que un judío, miembro de una religión que había anunciado al Mesías y luego lo había rechazado, se encontrara jurídicamente sobre un cristiano, representaba un contrasentido. Gregorio mismo lo enfatizó en varios de los extractos que ya hemos citado. Era un lenguaje similar al que se observaba en el Codex Theodosianus y en los cánones que hemos mentado, donde no solo se prohibía la posesión de esclavos sino el ejercicio de cargos públicos en los cuales los hebreos pudieran aparecer como superiores a los cristianos. La legislación visigoda, decenios más tarde y en un contexto de mucha mayor hostilidad, prohibió, incluso, el trabajo para los judíos a cambio de un pago. ${ }^{48}$ Tres siglos después, Agobardo de Lyon, ya en el mundo carolingio, se volverá a quejar de judíos que recaudaban impuestos arguyendo que utilizaban tal posición para convertir cristianos. ${ }^{49}$

Pero existían, también, razones prácticas. En ellas radica, entendemos, la preocupación, no solo gregoriana, sino del conjunto de legisladores, laicos y eclesiásticos que, siglo tras siglo, insistieron en la prohibición. Son varios los indicios que evidencian la tendencia judía a convertir a los esclavos. Tal fenómeno no era privativo de los judíos sino que era casi natural en una situación de desequilibrio de poder evidente potenciada en la esclavitud doméstica donde el trato era asiduo. Una realidad similar se observaba con las mujeres, por lo cual, si bien los matrimonios mixtos fueron prohibidos, primero se aplicó la interdicción sobre aquellos compuestos por un hombre judío y una mujer cristiana. ${ }^{50}$

$48 L V$. XII, 3, 1 prohibía a cualquier cristiano trabajar para un judío, incluso en condición de asalariado.

49 Existe una gran cantidad de bibliografía sobre la virulenta actitud de Agobardo frente a los judíos. Para obtener un panorama general, Albert 1996; SAVIGNi 2000; MALKiel 2003. Un actualizado estado de la cuestión, con un amplísimo repertorio bibliográfico, en LANGENWALTER 2009.

50 La prohibición del casamiento entre mujeres cristianas y hombres judíos data del año 329 o 339 (C.Th. XVI, 8, 6) mientras que la interdicción del lazo entre hombres cristianos y mujeres judías es del año 388 (C.Th. III, 7, 2 y IX, 7, 5 que, a través de un texto casi idéntico, prohíben ambos tipos de matrimonio). La diferencia en los tiempos se vincula a la mayor vulnerabilidad religiosa de la mujer, dada su posición subordinada. C.I., I, 9, 6, ya en el siglo VI, retoma las últimas dos leyes citadas. Sobre el tema, véase RABELLo 1988; BRUNDAGE 1988; Escribano PAÑo 2009. PAKTER (1988, 248-331), por su parte, dedica un valioso capítulo a la temática, no solo de los casamientos mixtos sino también de relaciones extramaritales y de los vínculos con los hijos. 
¿Qué beneficio obtenía un judío al convertir a un esclavo? ¿O era una mera cuestión de proselitismo? Gn. 17, 27 afirmaba que no solo Abraham sino también los esclavos nacidos en la casa y los comprados habían sido circuncidados. ${ }^{51}$ Naturalmente, no era forzoso extraer una norma del pasaje, pero existía la posibilidad de hacerlo. Una conclusión similar puede aplicarse a Ex. 12, 44, donde se sostiene que todo esclavo comprado por dinero comería la cena pascual tras haber sido circuncidado. ${ }^{52}$ Cierto es que existía, también, la posibilidad de mantener al esclavo con el estatuto de עבד כנעני (eved cnaaní, esclavo cananeo) ${ }^{53}$-hecho que no obligaba al dueño a liberarlo al séptimo año- pero ello impedía que pudiera llevar a cabo algunas de las tareas del hogar que se encontraban vedadas a los gentiles. Precisamente sobre ello legisló el Talmud Bavlí, poniendo de manifiesto, en diversos tratados, las limitaciones que poseía un gentil al servicio de un judío. En $b$ Yebamoth 46, por ejemplo, varios rabinos interpretaban que el vino que había entrado en contacto con prosélitos que habían sido circuncidados pero no sometidos a la ablución ritual -y que, por tanto, no calificaban como judíos- era considerado impuro, así como también la comida que habían cocinado ${ }^{54}$ En efecto, una lectura del mismo tratado Yebamoth fue más

51 Gn. 17, 27: "Y todos los varones de su casa, los nacidos en su casa, y los comprados a extraños por dinero, fueron circuncidados juntamente con él”.

52 Ex. 12, 44: "Todo siervo, comprado por dinero, a quien hayas circuncidado, podrá comerla [se refiere a la cena pascual]".

53 Véase, por ejemplo, la referencia en $L v .25,45-46$ : "También podréis comprarlos entre los hijos de los huéspedes que residen en medio de vosotros, y de sus familias, que viven entre vosotros, es decir, de los nacidos en vuestra tierra. Esos pueden ser vuestra propiedad y los dejaréis en herencia a vuestros hijos después de vosotros como propiedad perpetua. A estos los podréis tener como siervos; pero si se trata de vuestros hermanos, los hijos de Israel, tú, como entre hermanos, no le mandarás con tiranía". En el Talmud, como bien señala WACHOLDER (1956, 90-91) el estatuto de Eved cnaaní era el primer paso en la conversión de un esclavo gentil al judaísmo. Ello involucraba tanto la circuncisión como la ablución ritual. Tiempo después, y con otra ablución, el esclavo, ya manumitido, podía devenir judío completo. Hasta ese momento, solo estaba obligado a seguir los preceptos asignados a las mujeres.

54 B Yebamoth, 46a: "R. Hiyya B. Abba vino una vez a Gabla donde observó a mujeres judías que habían concebido de prosélitos que eran circuncisos pero no habían realizado la ablución ritual requerida; él también notó que los idólatras servían el vino judío y los israelitas lo bebían, y también observó que los idólatras cocinaban lupinos y los israelitas los comían; pero no habló de la materia en absoluto. Llamó, sin embargo, a R. Yohanan, al cual instruyó: 'Vaya a anunciar que sus niños son bastardos; que su vino está prohibido como vino nesek; y que sus lupinos están prohibidos como alimento cocinado por idólatras, porque son ignorantes de la Torah'. 'Que sus niños son bastardos', R. Johanan acordó con su opinión. R. Hiyya B. Abba estableció en nombre del R. Yohanan: 'Un hombre no puede convertirse en un prosélito apropiado a menos que haya sido circuncidado y también haya realizado la ablución ritual; cuando, por lo tanto, no se ha realizado ninguna ablución es tomado como idólatra'; y Rabbah B. Bar Hana indicó en nombre del R. Yohanan que si un idólatra o un esclavo cohabitó con la hija de un israelita, el niño [nacido de la unión] es un bastardo. 'Que su vino es prohibido como vino nesek', porque se dice de un gentil, 'mantente lejos; vete de los alrededores; no te acerques al viñedo'. 'Que sus lupinos se prohíban como alimento cocinado por idólatras, porque son ignorantes de la Torah'. ¿[Hubieran sido] permitidos si los hombres hubiesen conocido la Torah? Seguramente. R. Samuel B. R. Isaac indicó en nombre de Rab, 'ningún comestible que pueda ser ingerido crudo tiene la prohibición del alimento cocinado por idólatras', y puesto que los lupinos no pueden ser comidos crudos, la prohibición del alimento cocinado por idólatras debe aplicarse. R. Yohanan adopta la visión, tal como fue expresada en la segunda versión. R. Samuel B. R. Isaac indicó en el nombre de Rab, 'lo que no se sirve en una tabla real como un plato que se comerá con pan, no está conforme a la prohibición del alimento cocinado por idólatras. La razón, por lo tanto, es que ellos eran ignorantes de la Torah; si hubieran conocido la Torah [sus lupinos hubieran sido] permitidos" (traducción propia). Con vino nesek el Talmud implica "vino para libación", 
allá al establecer que los esclavos gentiles tenían un año para elegir si eran circuncidados o no. En caso de ser interrogados sobre la cuestión y oponerse a ello, debían ser vendidos no a un judío sino, en palabras del Talmud, a un idólatra. ${ }^{55}$ Se podía, sin embargo, conservar al esclavo por tiempo indefinido -siempre y cuando respetara las גר תושב גeyes noájidas, lo cual implicaba el abandono de la "idolatría"- en calidad de (guer toshav, extranjero residente). ${ }^{56}$ Debemos resaltar, no obstante, que, al igual que la Biblia, el texto talmúdico no presenta definiciones claras sobre el tema y, por ende, las posibilidades de interpretación eran amplias. ${ }^{57}$

Cierto es que el Talmud no refleja stricto sensu la realidad de su época y es sumamente problemático extrapolar las conclusiones de su análisis a Europa occidental en un tiempo en el cual no está claro con qué velocidad se desplazaban las ideas surgidas en Babilonia y Palestina hacia los colectivos judíos de Italia, Hispania y Galia. Pero si sumamos los antecedentes bíblicos, los mencionados pasajes talmúdicos, la iteración de la normativa imperial y diversos casos presentes en la literatura cristiana podemos concluir que, efectivamente, existía una tendencia entre los judíos a convertir a sus esclavos. ${ }^{58}$

Dentro del material cristiano consideramos pertinente resaltar dos casos. El primero, una carta de Gelasio I (Papa entre 492 y 496) en la que se informa acerca de un esclavo cristiano que se había refugiado en una iglesia alegando que su dueño judío lo había circuncidado:

Judas, quien se manifiesta de condición judía, afirma que un esclavo perteneciente a él, el cual, sostiene, había sido procurado unos años antes, escapó ahora hacia la iglesia de Venafro; según manifiesta el tono del petitorio anexo, ese [el cristiano] dice que la señal de la circuncisión le fue impresa recientemente por su superior, a pesar de ser cristiano desde la infancia. Por esa razón, vuestra solicitud examine la verdad de las cosas entre los dos diligente y fielmente, de modo que ni la religión parezca

asociándolo al vino utilizado por idólatras para sus ofrendas y, por tanto, prohibido. B Avodah Zarah 57a también menciona el hecho de que el vino, al entrar en contacto con un gentil, se convierte en impuro.

$55 B$ Yebamoth $48 \mathrm{~b}$ trata de una larga discusión sobre si se debe retener o no a esclavos incircuncisos. Un pasaje es revelador: "Rab Joshua hijo de Levi dijo: 'Si un hombre compra un esclavo de un idólatra y el esclavo rechaza ser circuncidado, debe permanecer con su nuevo dueño por 12 meses. [Si en ese tiempo] no se circuncidara, debe ser vendido nuevamente a los idólatras"” (traducción propia).

56 Véase, para las leyes noájidas, a NovaK 2011. Algunas definiciones sobre el carácter de Guer toshav se dan en b Avodah Zarah 64b: "¿Quién es guer toshav? Cualquier [gentil] que promete en presencia de tres testigos no adorar ídolos. Esta es la afirmación de Rab Meir. Pero los sabios declaran: cualquier [gentil] que acepte sobre sí mismo los siete preceptos que los hijos de Noé aceptaron" (traducción propia).

57 Sobre el estatuto de los esclavos tanto en la Biblia como en el Talmud, véase, entre otros a KAHN 1867, 138-148; Wacholder 1956; Urbach 1979; Piatelli 1985; Garnsey 1999; NovaK 2006 y 2011; Lemche 2015; HEZSER 2015.

58 Francesco LuCREZI $(1994,226-229)$ se opuso a esta línea considerando que no existían impulsos bíblicos o talmúdicos categóricos tendentes a convertir a los esclavos a partir de coacción, directa o indirecta. Como hemos demostrado aquí, tanto el texto bíblico como la literatura rabínica establecen condiciones de posibilidad para la conversión del esclavo y motivaciones indirectas para ello. Lucrezi, además, parece considerar que los judíos se limitaban a seguir sus propias normas, sin tener en cuenta que también se encontraban fuertemente influenciados por la legislación romana y la noción de superioridad frente al servus que esta conllevaba. No tuvo en cuenta, tampoco, el resto de las evidencias extrajurídicas que hemos presentado aquí. 
violada ni el esclavo, mintiendo con esta objeción, logre evitar las leyes competentes de dominio. ${ }^{59}$

El pontífice instruye a los obispos de la región para que investiguen el asunto, afirmando que ni la religión cristiana ni las normas sobre esclavos debían ser violadas. De hecho - como se ve en la cita-Gelasio parece dudar de la veracidad de lo narrado por el esclavo. No obstante, de sus órdenes se decanta que era verosímil que un judío convirtiera a su esclavo. Solo en ese caso -Gelasio parece apegarse a las primeras normas del Codex Theodosianus- la liberación del esclavo debía realizarse.

Un análisis pormenorizado del canon 31 del concilio llevado a cabo en Orleans en el año 541 permite observar algunos de los mecanismos a partir de los cuales, según afirmaban los sacerdotes, los judíos podían estimular la conversión de sus subordinados:

También decidimos que debe ser observado que si se presumiera que un judío hiciera judío a un prosélito -aquel llamado extranjero- o si una vez hecho cristiano, lo indujera hacia la superstición judaica o si creyera que su esclava debe casarse con un judío, o si -bajo promesa de libertad- hiciera judío a uno nacido de padres cristianos, sea multado con la libertad del esclavo. Se prohíbe a quien - nacido de los cristianosse hizo judío a condición de ser manumitido, mantener la libertad permaneciendo en el rito judaico; tal condición no tendrá valor porque es injusto que la libertad sea mantenida por quien, viniendo de padres cristianos, quiere adherir a los cultos judíos. ${ }^{60}$

Estamos, si damos crédito a la disposición, ante diversos mecanismos utilizados por los judíos para lograr la conversión de los esclavos. Puede rastrearse, en primer lugar, un determinado nivel de presión, tanto para aquel llamado advena como para la ancilla. Pero, más importante aún, el pasaje hacia el judaísmo es acicateado a través de la promesa de liberación. Podríamos preguntarnos, sin embargo, con qué fin se buscaría liberar a un esclavo a condición de hacerlo judío si, precisamente, la búsqueda del cambio religioso tenía por objetivo tornarlo compatible con ciertos quehaceres del hogar regulados por la normativa mosaica. Una primera respuesta podría incluir la existencia de un proselitismo activo entre los judíos, aunque tal realidad fue debatida $-\mathrm{y}$ desechada- incluso en el período previo, donde aún no existía un desequilibrio

59 Gelasio I, Fragmentum 43: Judas, qui Judaicae professionis exstitit, mancipium juris suis, quod ante paucos annos se assserit comparasse, nunc ad ecclesiam Venefranam confugisse suggessit, sicut petitorii tenor anexus ostendit, eo quod dicat sibi ab infantia Christiano nuper a praelato domino signaculum circumcisionis infixum. Quapropter diligenter vestra inter utrumque sollicitudo rerum fideliter examinet veritatem, quatenus nec religio temerata videatur, nec servus hac objectione mentitus competentis jura domini declinare contendat (texto latino tomado de S. Simonsohn (ed.), The Apostolic See and the Jews. Documents: 492-1404, Toronto, 1988, 2-3).

60 Id etiam decernimus observandum, ut, si quicumque Indaeos prosilitum, qui advina dicitur, Iudaeum facire praesumpserit aut Christianum factum ad Iudaeicam superstitionem adducire vel si Iudaeo Christianam ancillam suam crededirit sociandam vel si de parentibus Christianis natum ludeum sub promissione fecerit libertatis, mancipiorum amissione multetur. Ille veto, qui de Christianis natus Iudaeus factus est, si sub condicione fierit manumissus, ut in ritu ludaeico permanens habeat libertatem, talis condicio non valebit, quia iniustum est, ut ei libertas maneat, qui de Christianis parentibus veniens ludaicis vult cultibus inherere. 
de poder tan marcado entre ambas religiones. ${ }^{61}$ La segunda opción, más verosímil a nuestro entender, es que se tratara de una manumisión diferida, o sea que el esclavo -ya judío y por tanto capaz de realizar todas las actividades del hogar- debía continuar en calidad de servus durante determinada cantidad de tiempo antes de la liberación. De todos modos, una vez realizada la manumisión, continuaba existiendo un vínculo de dependencia entre el ex esclavo y quien lo había liberado, por lo cual la práctica continuaría siendo provechosa para los judíos.

El impulso hacia la conversión de los esclavos se comprueba, por último, en una epístola del Registrum. Escribe Gregorio al obispo de Catania en abril del 596:

Un hecho completamente execrable y enemigo de las leyes ha llegado a nosotros, el cual, si es cierto, acusa vehementemente a tu fraternidad, dado que prueba que ella es culpable de poca preocupación. Descubrimos que los samaritanos que viven en Catania han comprado esclavos paganos y se han arrogado el derecho de circuncidarlos con atrevida temeridad. ${ }^{62}$

Si bien estamos frente a samaritanos y ante esclavos paganos, tenemos un caso patente de avance religioso sobre servi llevado a cabo por individuos que, aunque no judíos, no se encontraban tan distantes, al menos a ojos de algunos hombres de Iglesia, de estos. ${ }^{63}$ Gregorio, sin duda, pudo trazar paralelismos con la situación de los esclavos bajo control judío.

El conjunto de evidencias indica, entonces, que la conversión de esclavos era una práctica frecuente entre los judíos. No existían preceptos inequívocos que la fomentaran abiertamente, pero la propia arquitectura del ritual judío estimulaba la praxis. En tiempos gueónicos son muchos los responsa refiriendo a casos de conversión de esclavos cristianos y musulmanes al judaísmo. ${ }^{64}$ Avanzado el Medioevo encontramos, aún, a judíos sicilianos que circuncidaban a sus esclavos, la mayoría de ellos de origen musulmán. ${ }^{65}$

61 La década de los 90 presenció la aparición de diversos textos que inclinaron el consenso contra la idea, que había postulado con claridad Marcel Simon, de un proselitismo judío activo hasta el primer tercio del siglo V. Estos fueron McKNight 1991; Will - ORRIEUX 1992 y GoOdMAN 1994. En oposición a esta postura, entre otros, Feldman 1993; Carleton Paget 1996 y Borgen 1998. De todos modos, insistimos en que para el periodo altomedieval fueron muy pocos los autores que consideraron la posibilidad de una actividad proselitista agresiva por parte de los judíos. En tal línea se manifestó Bernhard BLuMENKRANZ (1960) quien, a su vez, fue puesto en tela de juicio por el propio Simon $(1964,486)$ en el Post-Scriptum de su Verus Israël.

62 Gregorio Magno, Registrum, VI, 30 [abril, 596]: Res ad nos omnino detestabilis et legibus inimica peruenit quae, si uera est, fraternitatem tuam uehementer accusat, quia eam de minori sollicitudine probat esse culpabilem. Comperimus autem quod Samaraei degentes Catenae pagana mancipia emerint atque ea circumcidere ausu temerario praesumpserint.

63 No es este el espacio para explorar la problemática samaritana. Información valiosa sobre la relación entre los samaritanos y los judíos en Coggins 1975; Dexinger 1981; Rabello 1987-1988; Pummer 2002; HJelm 2004; VAN Der Horst 2006.

64 WACHOLDER 1956.

65 Véase, por ejemplo, a BreSc 2007. El autor, enfocándose en Sicilia, comprueba la continuidad de la utilización de esclavos domésticos por parte de los judíos. Corrobora, a su vez, la tendencia de tales esclavos a abrazar el judaísmo o, cuanto menos, acercarse a sus prácticas. 
Podemos, ya, comprender por qué más de un tercio de las epístolas gregorianas destinadas a problemáticas vinculadas al judaísmo se refieren al tema de los esclavos. Efectivamente, porque existía un importante grado de presión, por parte de los judíos, hacia la conversión de sus esclavos; hecho que ya había sido advertido por legisladores laicos y religiosos. Gregorio conocía la profusa existencia de normas sobre el tema y llegó a observar tal tipo de práctica, como ha quedado patente en el caso samaritano. A ello se adicionaba el peso simbólico de la subordinación de un cristiano por parte de un judío. Podríamos preguntarnos si Gregorio estaba al tanto de las tradiciones mosaicas o si su conocimiento se limitaba a la existencia empírica de conversiones de esclavos, pero el epistolario es renuente a proveer una respuesta de ese calibre.

Más allá de las causas del fenómeno, era inadmisible, para el obispo de Roma, dejar a los judíos la posibilidad de expandirse. El judaísmo que permitía Gregorio Magno debía renunciar a la difusión; estar cerrado sobre sí mismo. Debía ser, incluso, silencioso. En línea con Agustín, la religión de Moisés podía continuar solo en estado vegetativo, como una reliquia que manifestaba el error de haber rechazado a Cristo.

\section{Bibliografía}

ACERBI, S. (2006): Entre Roma y Bizancio: la Italia de Gregorio Magno a través de su Registrum epistularum (=Signifer. Monografías y Estudios de Antigüedad Griega y Romana 23), Madrid.

Albert, B. S.

(1976): "Un nouvel examen de la politique anti-juive wisigothique", Revue des études juives 135/1-3, 3-29.

(1996): “Aduersus Iudaeos in the Carolingian Empire”, [en] O. Limor-G. Storumsa (eds.), Contra Iudaeos. Ancient and Medieval Polemics between Christians and Jews (=Texts and studies in medieval and early modern Judaism 10), Tübingen, 119-142.

AA.VV.

(1991): Gregorio Magno e il suo tempo. XIX incontro di studiosi dell'antichità cristiana in collaborazione con l'École Française de Rome. Roma, 9-12 maggio, 1990 (=Studia Ephemeridis «Augustinianum» 33), Roma.

(2004): Gregorio Magno nel XIV centenario della morte (Roma, 22-25 ottobre 2003), (=Atti dei convegni Lincei 209), Roma.

BACHRACH, B. (1977): Early Medieval Jewish Policy in Western Europe, Minneapolis.

Baltrusch, E. (1994): "Gregor der Große und sein Verhältnis zum Römischen Recht am Beispiel seiner Politik gegenüber den Juden”, Historische Zeitschrift 259/1, $39-58$ (http:// dx.doi.org/10.1524/hzhz.1994.259.jg.39).

Bammel, E. (1991): “Gregor der Grosse und die Juden”, [en] AA.VV., 1991, 283-291.

Batiffol, P. (1928): Saint Grégoire le Grand, Paris.

Blumenkranz, B. (1960): Juifs et Chrétiens dans le monde occidental 430-1096 (=Études juives 2), Paris. 
Boesch Gajano, S.

(1979): "Per una storia degli ebrei in Occidente tra Antichità e Medioevo. La testimonianza di Gregorio Magno", Quaderni Medievali 8, 12-43.

(2004): Gregorio Magno alle origini del Medioevo (=Sacro/santo, nuova serie 8), Roma.

Borgen, P. (1998): "Proselytes, Conquest, and Mission", [en] P. Borgen et alii (eds.), Recruitment, Conquest and Conflict. Strategies on Judaism, Early Christianity and the Greco-Roman World, Atlanta, 57-77.

Bresc, H. (2007): "La schiavitù in casa degli ebrei siciliani tra tre e quattrocento", Quaderni Storici 126, 679-698 (http://dx.doi.org/10.1408/25914).

Brundage, J. (1988): “Intermarriage between Christians and Jews in Medieval Canon Law”, Jewish History 3/1, 25-40 (http://dx.doi.org/10.1007/BF01667346).

Carleton Paget, J. (1996): "Jewish Proselytism at the Time of Christian Origins: Chimera or Reality?", Journal for the Study of the New Testament 62, 65-103 (http://dx.doi.org/10. 1177/0142064X9601806204).

Cavadini, J. (ED.), (1995): Gregory the Great. A Symposium (=Notre Dame Studies in Theology 2), Notre Dame, Ind.

Coggins, R. (1975): Samaritans and Jews: The Origins of Samaritanism Reconsidered, Oxford.

CoHen, J. (1999): Living Letters of the Law: Ideas of the Jew in Medieval Christianity, Berkeley.

CRACCO RugGINI, L. (1995): Economia e società nell'Italia annonaria: rapporti fra agicoltura e commercio dal IV al VI secolo d.C., Bari (1 ${ }^{\mathrm{a}}$ ed. Milano, 1961).

Cremascoli, G. - Degl'Innocenti, A. (eds.), (2008): Enciclopedia gregoriana, Firenze.

DAGEns, C. (1977): Saint Grégoire le Grand. Culture et expérience chrétiennes (=Collection des études augustiniennes. Série Antiquité 71), Paris.

De Bonfils, G.

(1992): Gli schiavi dagli ebrei nella legislazione del IV secolo. Storia di un divieto (=Facoltà di Giurisprudenza: Pubblicazioni della Facoltà Giuridica dell'Università di Bari 103), Bari.

(1995): "L'obbligo di vendere lo schiavo cristiano alla Chiesa e la clausola del 'competens pretium", Atti dell'Accademia Romanistica Constantiniana 10, 503-528.

DeXINGER, F. (1981): "Limits of Tolerance in Judaism: The Samaritan Example”, [en] E. Sanders et alii (eds.), Jewish and Christian Self-Definition, London, vol. 2, 88-114.

Dudden, F. (1905): Gregory the Great. His Place in History and in Thought, New York.

Escribano PAÑo, Ma V. (2009): "Uniones mixtas y adulterio en C.Th. III, 7, 2 = IX, 7, 5. 388", [en] AA.VV., Il matrimonio dei cristiani: Esegesi biblica e diritto romano (=Studia Ephemeridis «Augustinianum» 114), Roma, 273-294.

Feldman, L. (1993): Jew and Gentile in the Ancient World: Attitudes and Interactions from Alexander to Justinian, New Jersey.

Fontaine, J. et aliI (EDS.), (1986): Grégoire le Grand. Actes du colloque international du CNRS, Chantilly, 15-19 septembre, 1982, Paris.

GARnsEy, P. (1999): Ideas of Slavery from Aristotle to Augustine, Cambridge. 
GonzÁlez SALinero, R.

(1998): "Los judíos y la gran propiedad en la Hispania tardoantigua: el reflejo de una realidad en la Passio Mantii", Gerión 16, 437-450.

(1999): "Catholic Anti-Judaism in Visigothic Spain", [en] A. Ferreiro (ed.), The Visigoths. Studies in Culture and Society (=The medieval Mediterranean 20), Leiden-Boston-Köln, 123-150.

(2000): Las conversiones forzosas de los judios en el reino visigodo (=Escuela Española de Historia y Arqueología en Roma. Serie Histórica 2), Roma.

(2012): "Una elite indeseable: los potentiores judíos en la España Visigoda", [en] J. Sánchez-Lafuente Pérez - J. Avello Álvarez (eds.), El mundo judio en la Península Ibérica: sociedad y economía, Cuenca, 5-18.

Goodman, M. (1994): Mission and Conversion. Proselytizing in the Religious History of the Roman Empire, Oxford (http://dx.doi.org/10.1093/acprof:oso/9780198263876.001.0001).

HARPER, K. (2011): Slavery in the Late Roman World, AD 275-425, Cambridge (http://dx.doi. org/10.1017/CBO9780511973451).

Hezser, C. (2015): “Slavery: Rabbinic Literature”, [en] Strawn (ed.), 2015, 312-319 (http:// dx.doi.org/10.1093/acref:obso/9780199843305.001.0001).

HJelm, I. (2004): "What do Samaritans and Jews have in Common? Recent Trends in Samaritan Studies", Currents in Biblical Research 3/1, 9-59 (http://dx.doi.org/10.1177/147699 3X0400300103).

JUSTER, J.

(1912): La condition légale des juifs sous les rois Visigoths, Paris.

(1914): Les Juifs dans l'Empire Romain. Leur condition juridique, économique et sociale, Paris.

KaHn, Z. (1867): L'esclavage selon la Bible et le Talmud, Paris.

Katz, S. (1993): "Pope Gregory the Great and the Jews", The Jewish Quarterly Review 24, 113-136 (http://dx.doi.org/10.2307/1451470).

Katz, S. (ED.), (2006): The Cambridge History of Judaism IV. The Late Roman-Rabbinic Period, Cambridge (http://dx.doi.org/10.1017/CHOL9780521772488).

LAHAM COHEN, R.

(2008): "Entre Hostes y Habitatores. Los judíos en la cosmovisión de Gregorio Magno", Limes 20, 113-132.

(2011): "En torno a motivaciones y efectos del discurso antijudío: el caso de los Moralia in Iob de Gregorio Magno", Polis 23, 115-151.

(2013): Judios hermenéuticos y judios históricos en la obra de Gregorio Magno, Tesis Doctoral, Universidad de Buenos Aires.

(2013a): "Tópicos antijudíos en las Homiliae in Hiezechihelem prophetam de Gregorio Magno", Anales de Historia Antigua, Medieval y Moderna 46, 281-308.

(2015): "Vas uacuum et signatum. La imagen del judío en los Dialogi y el problema de la autoría gregoriana", Revue des Études Juives 174/3-4, 295-324 (http://dx.doi.org/10.2143/ REJ.174.3.3122584).

(2015a): "Theological Anti-Judaism in Gregory the Great", Sefarad 75/2, 225-252 (http:// dx.doi.org/10.3989/sefarad.015.008). 
Langenwalter, A. (2009): Agobard of Lyon: An Exploration of Carolingian Jewish-Christian Relations, Doctoral Thesis, University of Toronto.

Lemche, N. (2015): “Slavery: Ancient Near East and Hebrew Bible”, [en] Strawn (ed.), 2015, 302-306 (http://dx.doi.org/10.1093/acref:obso/9780199843305.001.0001).

LINDER, A.

(1987): The Jews in Roman Imperial Legislation, Detroit.

(1997): The Jews in the Legal Sources of the Early Middle Ages, Detroit.

LuCREZI, F. (1994): “CTh. 16.9.2: Diritto romano-cristiano e antisemitismo”, Labeo. Rassegna di diritto romano 40, 220-234.

Makuja, D. (2009): “Gregory the Great, Roman Law and the Jews: Seeking 'true' Conversions", Sacris Erudiri 48, 35-76 (http://dx.doi.org/10.1484/J.SE.1.100554).

Malkiel, D. (2003): “Jewish-Christian Relations in Europe, 840-1096”, Journal of Medieval History 29, 55-83 (http://dx.doi.org/10.1016/S0304-4181(02)00055-6).

MARKUS, R.

(1995): "The Jew as a Hermeneutical Device: The Inner Life of a Gregorian Topos”, [en] Cavadini (ed.), 1995, 1-15.

(1997): Gregory the Great and his World, Cambridge (http://dx.doi.org/10.1017/ CBO9781139171236).

Martin, C. - Nemo-Pekelman, C. (2008): "Les Juifs et la cité. Pour une clarification du statut personnel des juifs de l'Antiquité Tardive à la fin du royaume de Tolède (IVe-VIIe siècles)", Antiquité Tardive 16, 1-24 (http://dx.doi.org/10.1484/J.AT.3.17)

McKnight, S. (1991): A Light among the Gentiles. Jewish Missionary Activity in the Second Temple Period, Minneapolis.

NeIL, B. - Dal Santo, M. (EDS.), (2013): A Companion to Gregory the Great, Leiden-Boston (http://dx.doi.org/10.1163/9789004257764).

Nemo-Pekelman, C. (2010): Rome et ses citoyens juifs (IV $V^{e} V^{e}$ siècles), Paris.

NovaK, D.

(2006): “Gentiles in Rabbinic Thought”, [en] Katz (ed.), 2006, 647-662 (http://dx.doi. org/10.1017/CHOL9780521772488.027).

(2011): The Image of the Non-Jew in Judaism. The Idea of Noahide Law, Oxford.

PAKter, W. (1988): Medieval Canon Law and the Jews, Medieval Canon Law and the Jews (=Münchener Universitätsschriften: Abhandlungen zur rechtswissenschaftlichen Grundlagenforschung 68), Ebelsbach.

Parkes, J. (1961): The Conflict of the Church and the Synagogue. A Study in the Origins of Antisemitism, New York (1 ${ }^{\mathrm{a}}$ ed. 1934).

PÉgolo, L. - Noce, E. - LAham Cohen, R. (2013): “El impacto del género literario y del rol social del emisor en el discurso antijudío (siglos IV a VII): Prudencio de Calahorra, Cromacio de Aquileya y Gregorio Magno", Florentia Iliberritana 24, 153-175.

Pellegrini, P. (2010): I concili Gallici, 2, Roma.

Piatelli, D. (1985): "Lo status dello schiavo liberato in Israele", [en] F. Parente (ed.), Atti del III Convegno tenuto a Idice, Bologna, 9-11 Novembre, 1982, Roma, 47-66.

Pummer, R. (2002): Early Christian Authors on Samaritans and Samaritanism: Texts, Translation and Commentary (=Texte und Studien zum antiken Judentum 92), Tübingen. 
RABELlo, A.

(1983-1984): "La conversione di Recaredo al cattolicesimo (587) e le sue ripercussioni sulla condizione giuridica degli Ebrei", Index 12/4, 377-390.

(1987-1988): Giustiniano, ebrei e samaritani alla luce delle fonti storico-letterarie, ecclesiastiche e giuridiche (=Monografie del Vocabolario di Giustiniano 2), Milano.

(1988): "Il problema dei matimoni fra ebrei e cristiani nella legislazione imperiale e in quella della chiesa (IV-VI secolo)", [en] AA.VV., Atti dell'accademia Romanistica Costantiniana: VII Convegno Internazionale, Napoli, 213-224.

(2006): "Justinian and the Revision of Jewish Legal Status", [en] Katz (ed.), 2006, 1073 1077 (http://dx.doi.org/10.1017/CHOL9780521772488.043).

Richards, J. (1980): Consul of God: The Life and Times of Gregory the Great, London-Boston.

SAVIGNi, R. (2000): “L'immagine dell'ebreo e dell'ebraismo in Agobardo di Lione e nella cultura carolingia", Annali di Storia dell'Esegesi 17/2, 417-461.

SERFASS, A. (2006): "Slavery and Pope Gregory the Great", Journal of Early Christian Studies 14, 77-103 (http://dx.doi.org/10.1353/earl.2006.0027).

Simon, M. (1964): Verus Israël. Étude sur les relations entre chrétiens et juifs dans l'Empire Romain (135-425), Paris (1 ${ }^{\mathrm{a}}$ ed. 1948).

STERN, J. (2000): “Israel et l'Église dans l'exégèse de Saint Grégoire le Grand”, [en] AA.VV., L'esegesi dei padri latini. Dalle Origini a Gregorio Magno (=Studia Ephemeridis «Augustinianum» 68), Roma, 675-689.

Stern, M. (1976): Greek and Latin Authors on Jews and Judaism. Volume II: From Tacitus to Simplicius, Jerusalem.

Straw, C. (1988): Gregory the Great. Perfection in Imperfection (=Transformation of the Classical Heritage 14), Berkeley-Los Angeles.

Strawn, B. (ED.), (2015): The Oxford Encyclopedia of the Bible and Law, Oxford (http:// dx.doi.org/10.1093/acref:obso/9780199843305.001.0001).

URBACH, E. (1979): The Laws regarding Slavery, New York.

VAn Der Horst, P. W. (2006): “Anti-Samaritan Propaganda in Early Judaism”, [en] Id., Jews and Christians in Their Graeco-Roman Context (=Wissenschaftliche Untersuchungen zum Neuen Testament 196), Tübingen, 134-150.

VERA, D.

(1986): "Forme e funzioni della rendita fondiaria nella tarda antichità", [en] A. Giardina (ed.), Società romana e impero tardoantico, vol. 1: Instituzioni, ceti, economie, RomaBari, 367-444.

(1998): "Le forme del lavoro rurale: aspetti della trasformazione dell'Europa romana fra tarda antichità e alto medioevo", [en] AA.VV., Morfologie sociali e culturali in Europa tra tarda Antichità e Alto Medioevo (=Settimane di Studio del Centro Italiano de Studi sull'Alto Medioevo XLV), Spoleto, 293-342.

WACHOLder, B. (1956): "The Halakha and the Proselyting of Slaves during the Gaonic Era", Historia Judaica 18/2, 89-106.

Will, E. - OrRieux, C. (1992): “Proselitisme juif?” Histoire d'une erreur, Paris. 